\title{
Experimental investigation of the effect of energy on the ore breakage
}

\author{
M. Akhondizadeh, ${ }^{\text {al }}$ And M. RezaeizadeH ${ }^{2}$ \\ 1 Mechanical Engineering Department of Sirjan University of Technology, Sirjan, Iran \\ 2 Graduate University of Advanced Technology, Kerman, Iran
}

Received 31 August 2015, Accepted 13 September 2016

\begin{abstract}
The comminution in Semi-Autogenous (SAG) mills depends on the impact conditions. It will be worthwhile to determine the efficient impact parameters. Drop weight test is employed to simulate the ball-flat impacts and study the effect of collision energy on ore breakage. Specimens are the copper ores of SAG mill feed of Sarcheshmeh copper complex. Minimum energy required for breakage is determined for each size. The size distribution of the broken ore due to the different specific input energies is determined and a relation is presented to predict it. Since the production of fine particles is important in SAG mill process, $t_{10}$ is measured and discussed. The results of present work can be used to optimize the comminution in SAG mills by controlling the milling parameters such as the mill speed, liner height and profile, feed size and ball size to achieve the efficient mill throughput.
\end{abstract}

Key words: Drop weight test / energy / impact / ore / comminution

\section{Nomenclature}

\begin{tabular}{|ll|}
\hline$E_{\mathrm{i}}$ & Specific input energy $(\mathrm{j} / \mathrm{g})$ \\
$E_{r}$ & Relative input energy \\
$E_{B t}$ & Breakage threshold energy per unit mass $(\mathrm{j} / \mathrm{g})$ \\
$G$ & Input linear momentum \\
$g$ & Gravity acceleration \\
$h$ & Falling height \\
$m$ & Ball mass \\
$m_{r}$ & Ore mass \\
$P$ & Passing \\
$v$ & Ball impact velocity \\
$X$ & Screen size ratio \\
\hline
\end{tabular}

\section{Introduction}

The size reduction mechanism in SAG mill includes attrition, abrasion and breakage. Breakage is the result of collision of ore with the falling particles including balls and large rocks. The size distribution of broken ore depends on the impact parameters. The fracture characteristics of variable ore sizes due to the different impact

\footnotetext{
${ }^{a}$ Corresponding author: m.akhondizadeh@gmail.com
}

conditions will be helpful in design stage to have efficient collisions in SAG mills. Empirical breakage distributions required in modeling of tumbling mills have been obtained by impact breakage of single particles of various sizes by the drop weight technique [1-3]. Morrison and Cleary [4] described various ways of extracting collision data from the DEM model and translating it into breakage estimates. Pourghahramani [5] studied the effect of ore characteristics on the particle shape to monitor breakage events occur in the industrial SAG mills as a function of ore hardness. Tavares [6] measured the fraction of the input energy that is used for particle breakage using the ultra-fast load-cell in a drop weight test apparatus. The breakage rates of three types of iron ore were studied experimentally by Weedon and Wilson [7]. Twin pendulum breakage machine was employed to determine breakage rates using a computer monitored laser.

Tavares and King [8] used the Ultrafast Load Cell (UFLC) to investigate the fracture of particles subject to impact. Three fundamental fracture characteristics including the particle fracture energy, the particle strength and the particle stiffness were measured. Genc et al. [9] designed a drop weight tester to analyze single particle impact breakage characteristics of different materials. Breakage parameter $t_{10}$ was used to represent the degree of size reduction which is assumed to be representative of the breakage product size distribution obtained from drop-weight tests. 


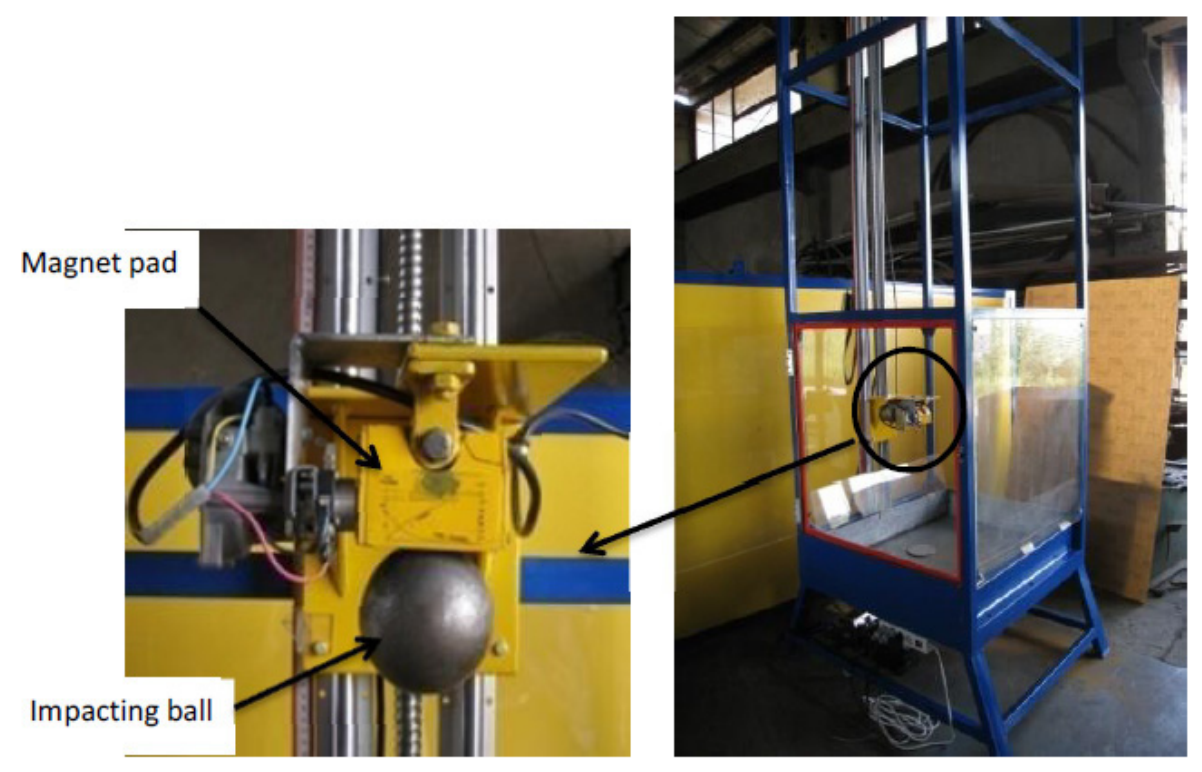

Fig. 1. Drop weight test machine (right) and ball and magnet pad (Left).

King and Bourgeois [10] described the operation of a precise apparatus for the measurement of the distribution of fracture energies among particles and the relationship between the breakage function and the impact energy.

Pauw and Mare [11] devised experiments for breakage of single ore particles of various sizes at varying levels of impact energy. They showed that the optimum level of the impact energy was highly dependent on the size of the particle to be broken, size of the final product and the efficiency of secondary breakage. Kapur et al. [12] presented a model for breakage of single particles as a function of the impact energy. Shi and Kojovic [13] modified a breakage probability model to describe the degree of impact breakage, $t 10$. The modified model had a form similar to the JKMRC breakage model, but with particle size and breakage properties incorporated explicitly in the model. Genc et al. (2014) used empirical variations in single particle impact breakage distribution data of eleven types of raw and one type of cement clinkers crushed in High Pressure Grinding Rolls (HPGRs) to analyze the size and energy level dependency of clinker breakage. Since in some cases, limitations of time, sample availability, and even cost, can prevent the conduction of drop weight tests Fernando et al. (2014) demonstrated how a laboratory cone crusher equipped with a power meter, in conjunction with Whiten-Awachie crusher model, has been used to quickly estimate the breakage parameters. Almost all mentioned references used the impact energy as an important parameter affecting in ore breakage.

In the present work a drop weight tester is employed to study the effect of impact energy and impact momentum on the size distribution of broken copper ore of different sizes. Relations are presented to evaluate the size distribution and $t_{10}$ of the broken ore considering the different breakage characteristics such as particle size, impact energy and product size distribution required. The material are fed in an operating SAG mill in Sarcheshmeh copper complex has not been studied to determine the effect of impact energy on breakage characteristics until now. It is first experimental study for such ore and results can be used for industries produce such materials. Moreover, the effect of momentum which is rarely considered in previous literatures has been evaluated in present work.

\section{Description of the drop weight test machine}

Single particle breakage test methods reviewed by Narayanan [2] include drop weight tests and twin pendulum experiments which the breakage mechanism is impact loading and slow compression tests where used to model the breakage occurring in mills. A drop weight test machine is employed for this aim one of them is illustrated in Figure 1. The impactor is steel ball which its energy is provided by gravity. Ball is released by disconnecting the electric circuit of a magnet piece. It is lifted to the specified height by means of a rotating spindle to provide the input energy which is evaluated by following equation:

$$
E=m g h
$$

In which $m$ is the ball mass, $g$ is the gravity acceleration and $h$ is the falling height. The ball diameter ranges from 30 to $100 \mathrm{~mm}$ in diameter and the maximum height is $2 \mathrm{~m}$. The maximum input energy will be about 80 joules. Specimens are copper ore positioned on a flat bed which is a rigid concrete peace. Rigidity confirms minimizing the bed energy absorption and transferring the maximum part of input energy to the specimen. Impacts can be recorded by a high speed camera (60 frames per second). An example of such records is illustrated in Figure 2 which 


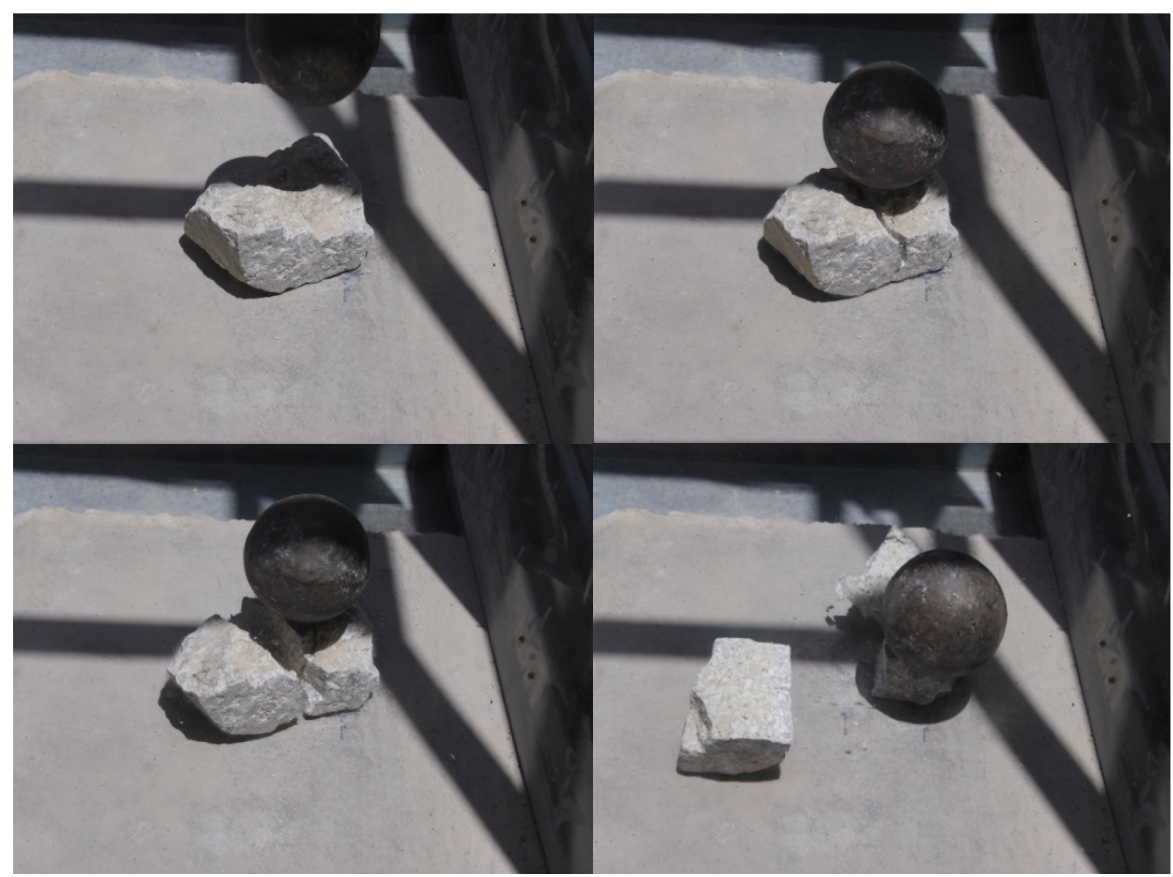

Fig. 2. Records of impact moment.

Table 1. Specimen size and mass.

\begin{tabular}{cccccc}
\hline Size fraction $(\mathrm{mm})$ & $15-19$ & $25-32$ & $38-45$ & $44-54$ & $110-120$ \\
\hline Mass $(\mathrm{g})$ & 8 & 22 & 100 & 158 & 2000 \\
\hline
\end{tabular}

shows the breakage process more detailed. The impact region is enclosed by the compact plastic walls which prohibit missing the broken parts. A portable panel is used to control the ball lifting and releasing.

\section{Experimental procedure}

The specimens are copper ores of Sarcheshmeh copper complex in sizes are given in Table 1. Experiments revealed that sizes over $120 \mathrm{~mm}$ require the breakage input energy which is beyond the machine capabilities. The specimens of each size are selected such that they have the minimum mass deviation (about $6 \%$ ) of which is given in Table 1. To have reliable results, applicable for operating SAG mill, the specimens prepared from the mill feed. Special care have been made to select identical, no defect and flat specimens. No additional process for specimen refinement has been done to avoid change of effective properties. The important note about the specimen shapes is that they should be possibly flat to effectively distribute and absorb the major part of impact energy. Experiments which we observed that this condition doesn't be achieved are repeated until a satisfactory impact is attained. Image of a specimen has been illustrated in Figure 2. Size of specimens is the minimum mesh which it passes of.

The collision enclosure is completely cleaned by the hand sweep. Breakage test is done and the resulting particles are completely swept and screened. The specimens are selected to be as possible semi-flat and the impact point is such set to have the center impacts on specimen and obtain the reliable results. There are three mechanisms resulting in size reduction in mill: Attrition, abrasion and breakage. The aim of present work is to improve breakage mechanism in SAG mill. For this aim the experimental work is an efficient technique. The physics of ore may have the secondary degree of importance after the impact energy. In spite of this, from the physical properties point of view, we tried to selected specimens having the minimum initial cracks and soft parts. They have been prepared from the identical bulks to have the same properties. So the minimum test errors may be produced from the physical property differences.

\section{Breakage threshold energy}

Experimental data revealed that the impact of a particle at a given energy level does not ensure that it actually absorb it [7]. The energy transfer efficiency depends on material type, impact energy level and loading geometry [8] whether ball-ball, ball- flat or flat-flat. Present impacts are all ball-flat. Depend on the input energy the collision may produce different size fractions as illustrated in Figure 3. For each specimen there is a minimum input energy $\left(E_{B t}\right)$ which maybe resulted in a least level of breakage. The least breakage is considered as loosing $10 \%$ of the initial specimen mass. To determine $E_{B t}$ several 


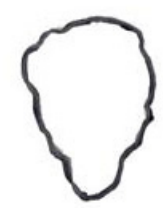

Original

Particle

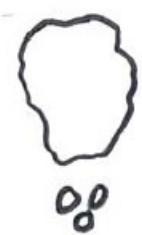

A

C

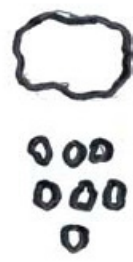

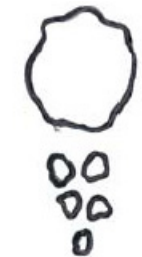

B

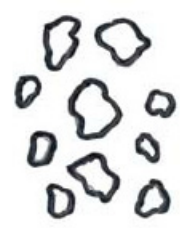

D
Fig. 3. Four levels of ore breakage.

samples of each size are impacted by increasing input energy until the least level of breakage be achieved. Curve fitting gives the following relation for prediction of the breakage threshold energy of specimens.

$$
E_{B t}=6.26 m_{r}^{-0.7}
$$

In which $E_{B t}$ is the breakage threshold energy per unit mass $(\mathrm{j} / \mathrm{gr})$ and $m_{r}$ is the specimen initial mass in gram.

\section{Product size distribution}

The experiments are performed to investigate the effect of input energy on the size distribution of broken copper ore The input energy is higher than the threshold energy. The following relation is suggested to predict the size distribution:

$$
P=\frac{E_{i}}{2 E_{B t}} X^{n}
$$

In which $P$ is the passing (passing mass to the initial particle mass), $E_{i}(\mathrm{j} / \mathrm{g})$ is the specific input energy, $E_{B t}$ $(\mathrm{j} / \mathrm{g})$ is the breakage threshold energy, $X$ is the screen size ratio (screen size to initial particle size) and $n$ is a parameter.

\section{Results and discussion}

The curve fitting gives for some specimens the appropriate values of $n=1.1$ and for others $n=1.25$. Figures 4-8 show the comparison of experimental data and predictions of Equation (3) for the given product size distribution.

As we can see in more cases the predictions have good accordance with the measurements. There is a tangible

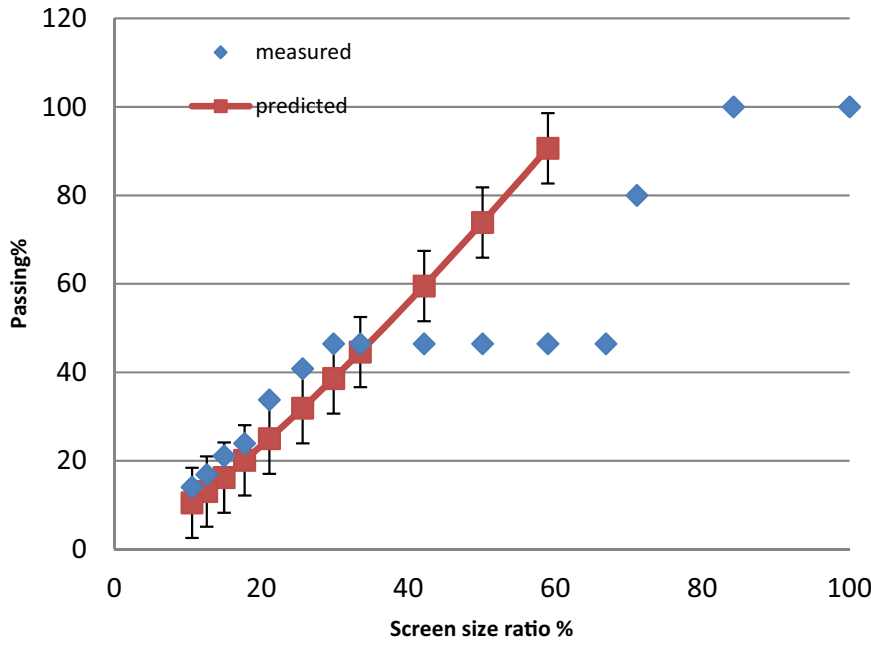

Fig. 4. Size distribution of ore $15-19 \mathrm{~mm}, E_{i}=2.12 \mathrm{j} / \mathrm{g}$, $E_{B t}=1.46 \mathrm{j} / \mathrm{g}, n=1.25$.

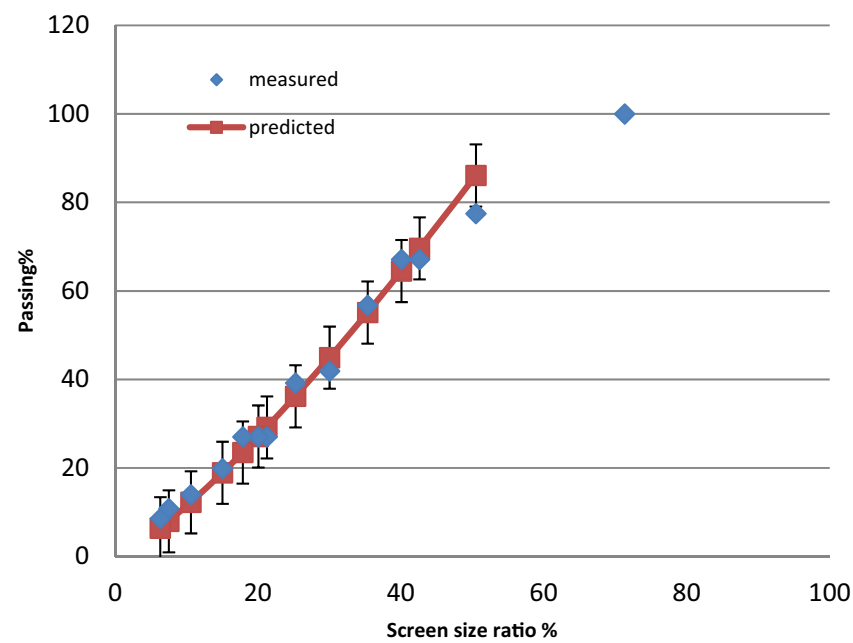

Fig. 5. Size distribution of ore $25-32 \mathrm{~mm}, E_{i}=1.6 \mathrm{j} / \mathrm{g}, E_{B t}=$ $0.7, n=1.25$.

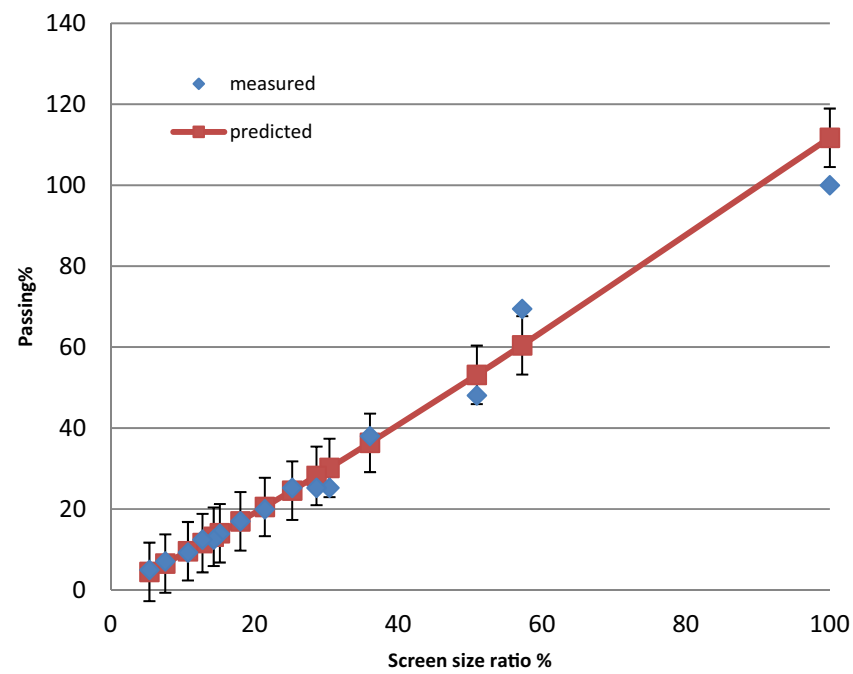

Fig. 6. Size distribution of ore $38-45 \mathrm{~mm}, E_{i}=0.8 \mathrm{j} / \mathrm{g}, E_{B t}=$ $0.25, n=1.1$. 


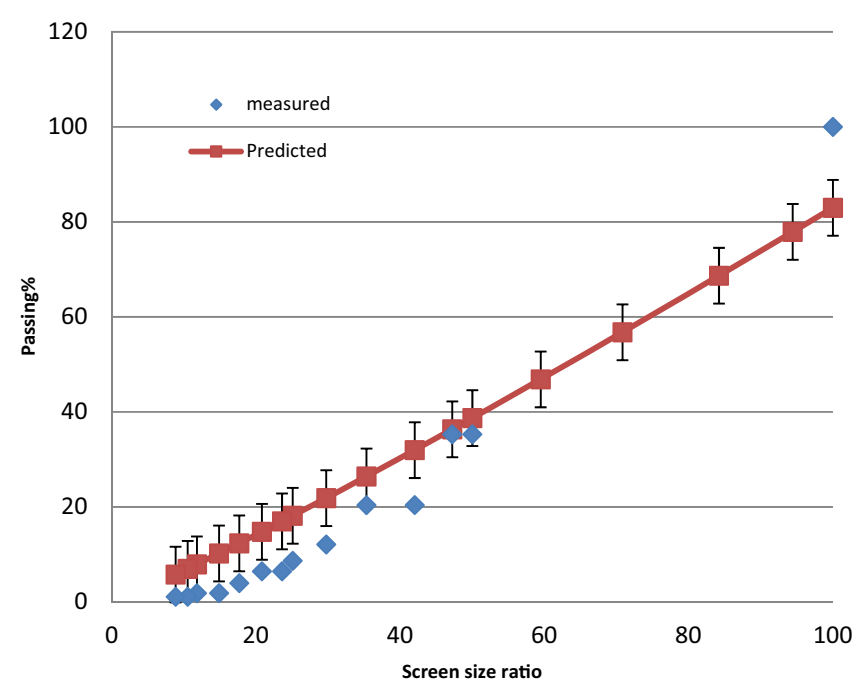

Fig. 7. Size distribution of ore $45-54 \mathrm{~mm}, E_{i}=0.21, E_{B t}=$ $0.18, n=1.1$.

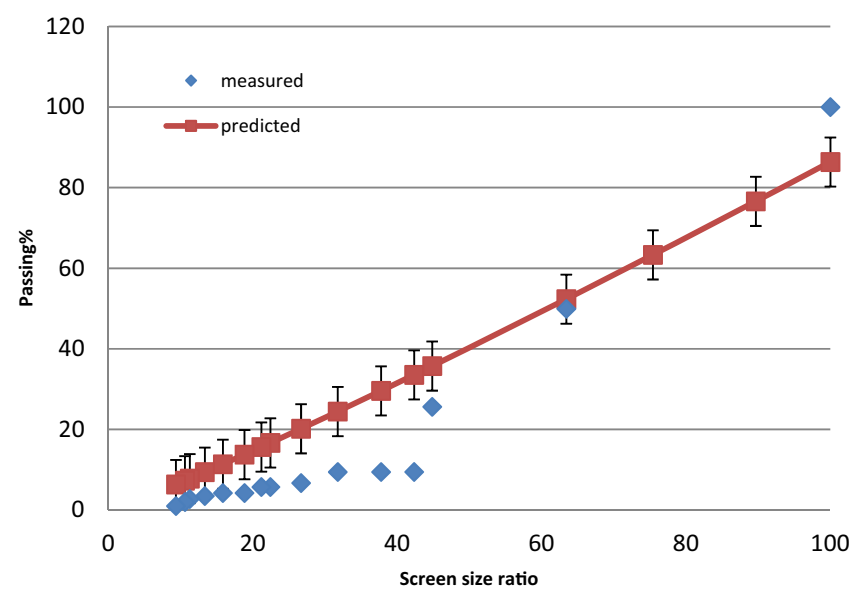

Fig. 8. Size distribution of ore $110-120 \mathrm{~mm}, E_{i}=0.04 \mathrm{j} / \mathrm{g}$, $E_{B t}=0.03, n=1.1$.

difference between measurements and predictions in sizes 15-19 $\mathrm{mm}$ and $110-120 \mathrm{~mm}$. For the size $110-120 \mathrm{~mm}$ a low level of breakage happens because that the input energy of $E_{i}=0.04 \mathrm{j} / \mathrm{gr}$ is close to the $E_{B t}=0.03$. Providing larger input energy is impossible for the present machine. As mentioned in previous sections the maximum input energy will be about $80 \mathrm{j}$ which will produce $E_{i}=80 / 2000=0.04 \mathrm{j} / \mathrm{g}$ for size $110-120 \mathrm{~mm}$. If it is possible to have higher input energy for this size the better accordance will be achieved.

The size distribution of broken parent sizes of 38-45, 45-54 and $110-120 \mathrm{~mm}$ is illustrated in figure 9 at the relative input energy of $E_{r}=E_{i} / E_{B t}=1.2$. As we can see identical size distribution will be achieved due to the same relative input energy.

The effect of input energy on the size distribution of a unique size at the different input energy is illustrated in Figures 10 and 11. As we can see in these figures more fine particles is produced as the relative input energy increases.
In comminution studies $t_{10}$ is defined as the percentage passing the $1 / 10$ th of the initial mean particle size [6]. If we only take into account the effect of energy on $t_{10}$, the following relation is the best fit to evaluate it for the current specimens.

$$
t_{10}=6 \ln \left(1+\left(\frac{E_{i}}{E_{B t}}\right)^{1.9}\right)
$$

Measured and evaluated $t_{10}$ of 16 tests for different sizes $(14-120 \mathrm{~mm})$ is illustrated in Figure 12. It gives a total comparison between experimental data and predicted results.

As we can see there is remarkable deviation between measured and evaluated $t_{10}$ if only energy be taken into account. To improve the theoretical relation, input linear momentum should be taken into account. The following relation gives $t_{10}$ which has the minimum deviation from the experimental data.

$$
\begin{aligned}
t_{10} & =9.8\left[\left(\frac{G}{m_{r}}\right)\left(\frac{E_{i}}{E_{B t}}\right)\right]^{0.63} \\
G & =m v
\end{aligned}
$$

In which $G$ is the linear momentum and $v$ is the ball impact velocity. Comparison of the evaluated $t_{10}$ by Equation (5) and measured ones is illustrated in Figure 13. It can be seen that Equation (5) better predicts $t_{10}$ at different impact conditions.

\section{Conclusions}

Drop weight machine is employed to study the effect of collision energy on ore breakage. The different ore sizes of SAG mill feed are impacted by steel ball. Several experiments are done for each size to determine the minimum energy required for breakage. A relation is suggested to predict this energy based on the experimental data. The size distributions of the broken ore due to the different specific input energies are determined. A relation is presented to predict the size distribution which gives a good accordance with the experimental results. Since the production of fine particles is important in SAG mill process, $t_{10}$ is measured and discussed. Results show that $t_{10}$ depends not only on the specific input energy but also the input momentum. A model is presented, taking into account the momentum and energy, to predict $t_{10}$. The model shows the appropriate accordance with the experimental results. The results of present work can be used to optimize the comminution in SAG mills by controlling the milling parameters such as the mill speed, liner height and profile, feed size and ball size to achieve the efficient mill throughput. 


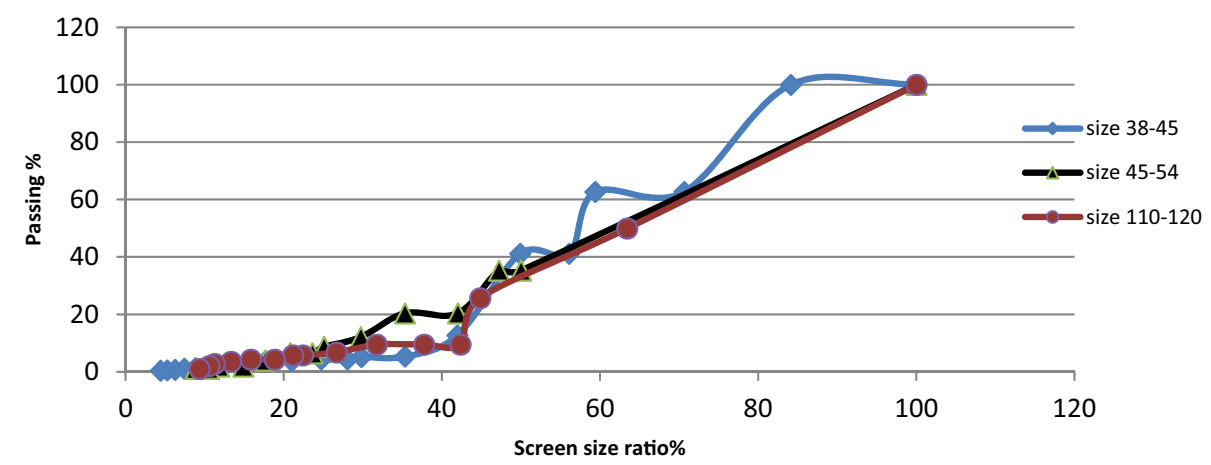

Fig. 9. Measured size distribution due to the same relative input energy of $E_{r}=1.2$.

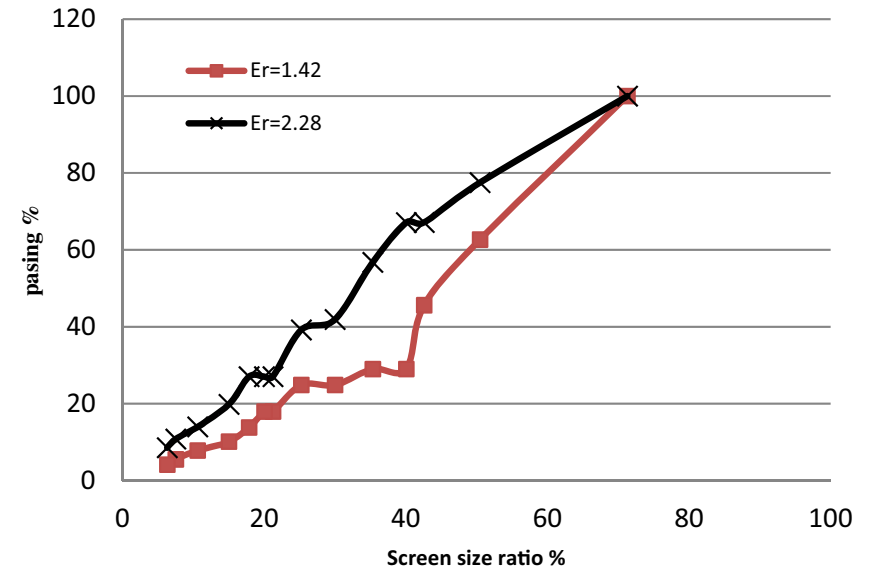

Fig. 10. Size distribution of ore $25-32 \mathrm{~mm}$ at the different input energy.

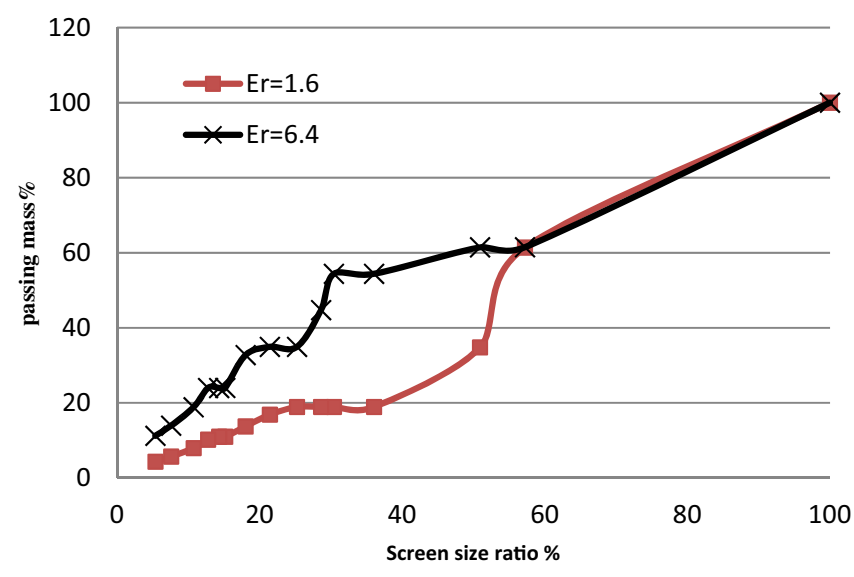

Fig. 11. Size distribution of ore $38-45 \mathrm{~mm}$ at the different input energy.

\section{References}

[1] S.S. Narayanan, Development of a Laboratory Single Particle Breakage Technique and Its Application to Ball Mill Modeling and Scale-up, (PhD Thesis) Julius Kruttschnitt Mineral Research Centre, The University of Queensland, Australia, 1985

[2] S.S. Narayanan, Single particle breakage tests: a review of principles and applications to comminution modelling,

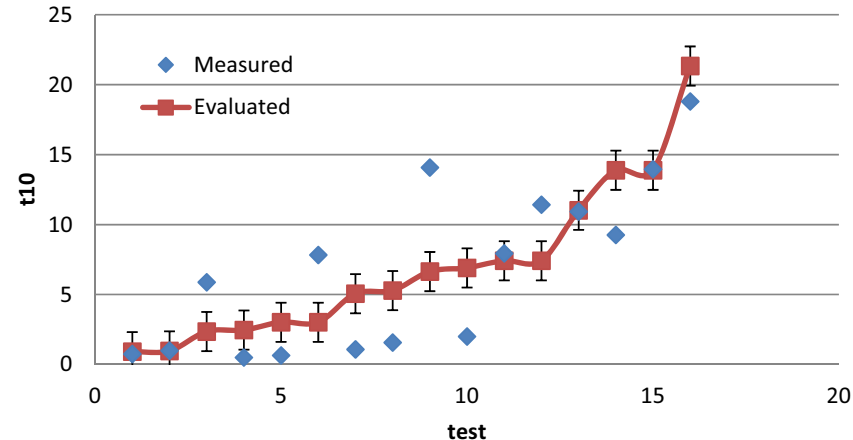

Fig. 12. Measured and evaluated $t_{10}$ for the current specimens at the different input energy (16 tests) (only energy has been taken into account).

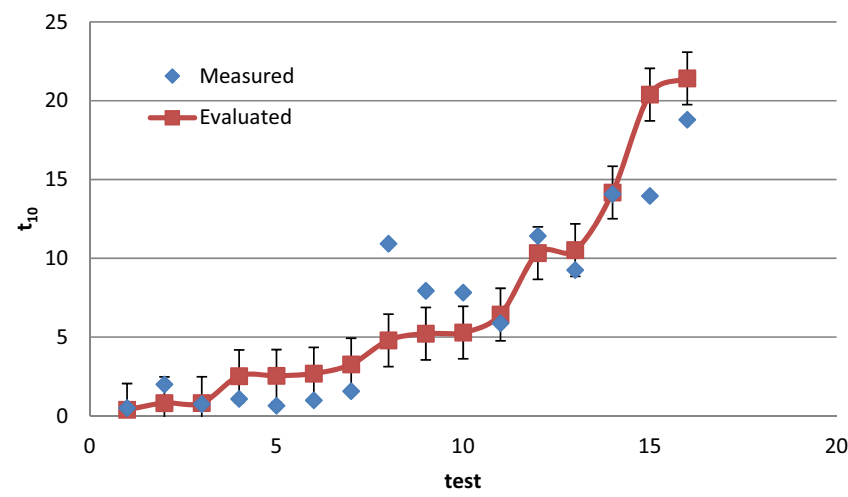

Fig. 13. Measured and evaluated $t_{10}$ by Equation (5) (momentum is also taken into account) at the different tests.

Bull. Proc. Australas. Inst. Min. Metall. 291 (1986) 49-58

[3] S.S. Narayanan, W.J. Whiten, Breakage characteristics of ores for ball mill modelling, Proc. Aus IMM 286 (1983) $31-39$

[4] R.D. Morrison, P.W. Cleary, Using DEM to model ore breakage within a pilot scale SAG mill, Miner. Eng. 17 (2004) 1117-1124

[5] P. Pourghahramani, Effects of ore characteristics on product shape properties and breakage mechanisms in industrial SAG mills, Miner. Eng. 32 (2012) 30-37

[6] L.M. Tavares, Energy absorbed in breakage of single particles in drop weight testing, Miner. Eng. 12 (1999) 43-50 
[7] D.M. Weedon, F. Wilson, Modelling iron ore degradation using a twin pendulum breakage device, Int. J. Miner. Process. 59 (2000) 195-213

[8] L.M. Tavares, R.P. King, Single-particle fracture under impact loading. I Int. J. Miner. Process. 30 (1998) 1-28

[9] O. Genc, L. Ergon, H. Benzer, Single particle impact breakage characterization of materials by drop weight testing. Fizykochemiczne Problemy Mineralurgii/Physicochemical Problems of Mineral Processing 2004 241-55

[10] R.P. King, F. Bourgeois, Measurement of fracture energy during single-particle fracture, Miner. Eng. 30 (1993) 353-67

[11] O.G. Pauw, M.S. Maré, The determination of optimum impact-breakage routes for an ore, Powder Technol. 31 (1988) 3-13
[12] P.C. Kapur, D. Pande, D.W. Fuerstenau, Analysis of single-particle breakage by impact grinding, Int. J. Miner. Process. 30 (1997) 223-36

[13] F. Shi, T. Kojovic, Validation of a model for impact breakage incorporating particle size effect, Int. J. Miner. Process. 30 (2007) 156-63

[14] Ö. Genç, A.H. Benzer, S.L. Ergün, Analysis of single particle impact breakage characteristics of raw and HPGRcrushed cement clinkers by drop weight testing, Powder Technol. 259 (2014) 37-45

[15] F.N. Magalhães, L.M. Tavares, Rapid ore breakage parameter estimation from a laboratory crushing test, Int. J. Miner. Process. 10 (2014) 49-54 